\title{
Natural colorants from filamentous fungi
}

\author{
Fábio Aurélio Esteves Torres ${ }^{1} \cdot$ Bruna Regina Zaccarim $^{1} \cdot$ Letícia Celia de Lencastre Novaes $^{2}$. \\ Angela Faustino Jozala $^{3}$ - Carolina Alves dos Santos ${ }^{4}$ - Maria Francisca Simas Teixeira ${ }^{5}$. \\ Valéria Carvalho Santos-Ebinuma ${ }^{1}$
}

Received: 29 October 2015 /Revised: 15 December 2015 / Accepted: 19 December 2015 / Published online: 18 January 2016

(C) Springer-Verlag Berlin Heidelberg 2016

\begin{abstract}
In the last years, there is a trend towards the replacement of synthetic colorants by natural ones, mainly due to the increase of consumer demand for natural products. The natural colorants are used to enhance the appearance of pharmaceutical products, food, and different materials, making them preferable or attractive. This review intends to provide and describe a comprehensive overview of the history of colorants, from prehistory to modern time, of their market and their applications, as well as of the most important aspects of the fermentation process to obtain natural colorants. Focus is given to colorants produced by filamentous fungal species, aiming to demonstrate the importance of these microorganisms and biocompounds, highlighting the production performance to get high yields and the aspects of conclusion that should be taken into consideration in future studies about natural colorants.
\end{abstract}

Valéria Carvalho Santos-Ebinuma

valeriac@fcfar.unesp.br

1 Department of Bioprocess and Biotechnology, School of Pharmaceutical Sciences, UNESP-Universidade Estadual Paulista, Rodovia Araraquara - Jaú Km 1, Araraquara, SP 14801-902, Brazil

2 Institute of Biotechnology, RWTH Aachen University, Worringerweg 3, 52074 Aachen, Germany

3 Department of Technological and Environmental Processes, Sorocaba University - UNISO, Sorocaba, SP, Brazil

4 Laboratory of Biomaterials and Nanotecnhology, University of Sorocaba (UNISO), Sorocaba, SP, Brazil

5 Culture Collection DPUA/UFAM, Federal University of Amazonas, Manaus, AM, Brazil
Keywords Natural colorants $\cdot$ Microorganisms $\cdot$ Filamentous fungi $\cdot$ Biomolecules $\cdot$ Bioprocess

\section{Introduction}

Color has always fascinated humans and plays an important role in the acceptability of products of several industrial segments, since consumers first judge the quality of a product by its color (Wrolstad and Culve 2011). For centuries, industries use additives to enhance or restore the original color of products and to ensure its uniformity between batches (Medeiros et al. 2012; Fernández-Lopez et al. 2013). Additives used to provide color to substances are called colorants and can be classified as pigments or dyes. The basic difference between them is their size and solubility (Saron and Felisberti 2006). Pigments are practically insoluble in the medium in which they are incorporated while dyes dissolve during application, losing their crystal or particulate structure in the process. Regarding the size, pigment particles are about $1-2 \mu \mathrm{m}$ and dyes are smaller than it. Furthermore, the difference between pigments and dyes is therefore due to physical characteristics rather than chemical composition (Patel et al. 2012). Natural colorants from microorganisms can be pigments or dyes. To this reason, in this review, it will be called colorants independent of the source.

From prehistoric times, humans have left their mark on environment in the form of painted images, whether in the form of simple handprints, works of fine art, or spray-can graffiti. Many American indigenous civilizations used body and hair painting to communicate. Prehistoric painters used the colorants available next to their homes. The colors yellow ochre, red ochre, and black were obtained from soot from burning animal fat and charcoal from fire (Barnett et al. 2006). Natural colorants, such as bixin, genipin, and 
andirobin, were used for esthetic, religious, and protection purposes (Saron et al. 2006).

Egyptians began to develop colorants in 4000 BC. They introduced washed colorants so they could obtain a more colorful and a more pure compound. In $3000 \mathrm{BC}$, they create the Egyptian blue, derived from calcium copper silicate. They also used malachite and azurite, green and greenish-blue colorants, respectively. These colorants were used in the Egyptian tomb paintings from the fourth dynasty (2613 BC to 2495 BC) and appeared too in European paintings from the fifteenth and sixteenth centuries (Barnett et al. 2006).

Tyrian purple was the first global colorant and was traded by the Phoenicians (Bechtold and Mussak 2009). Roman centurions used red colorants from the marine mollusk Murex sp. to dye their tunics, while the Egyptians and the Bretons used natural indigo, extracted from the plant Isatis tinctoria. Other colorants used at the same period to color clothes were saffron, extracted from plants, and cochineal carmine, obtained from animals (Zhang et al. 2006). Until the mid-nineteenth century, colorants were essentially obtained from animals and plants (Hill 1997).

In 1856, the English chemist William H. Perkin synthesized Mauve - also known as aniline purple, phenamine, or indisine - the first organic colorant. In 1862, the establishment of a factory that produced this colorant commercially marked the beginning of the modern dye industry (Sousa et al. 2008; Cañamares and Lombardi 2015). Since then, and with the development of alchemy and chemistry, various strongly colored inorganic compounds have been created and used extensively as colorants (Zhang et al. 2006). Therewith, natural colorants were rapidly replaced by chemically synthesized colorants at the end of the nineteenth century and continued until the twentieth century, due to their low cost, large-scale production, flexible location, homogeneity of composition, among others (Bechtold and Mussak 2009).

However, the chemically synthesized colorants were used during many years with little concern or tests regarding their safety. Later, toxicity tests performed by regulatory agencies, such as Food and Drug Administration (FDA), showed the toxic effect of these compounds in the dose administrated by the industries to give color to several substances. So as a result, synthetic colorants can cause significant environmental pollution and have been suggested that they can cause adverse toxicological effects (Malik et al. 2012), such as allergic reactions and intolerance (Wang et al. 2006) and carcinogenic effect (Pan et al. 2009), and affect children's behavior, being hyperactivity the most common disorder (Masone and Chanforan 2015).

As result, concerns about the safety of artificial colorants have been growing, which resulted in the implementation of numerous regulations in several countries, the reduction of the number of synthetic colorants approved for food use by the regulatory agencies (Pan et al. 2009; Rymbai et al. 2011), as well as the return of natural colorants to the market, particularly in the food sector (Mapari et al. 2010; Mirjalili et al. 2011; Sivakumar et al. 2011). According to a report by "ReportBuyer," the food color market is projected to reach $\$ 2.5$ billion by 2020 , growing at a compound annual growth rate (CAGR) of $4.5 \%$. The European food and beverage colorant market is estimated to grow at a CAGR of $7 \%$ from 2015 to 2020 (https://www.reportbuyer.com/product/ 3024599/uk-food-colorants-market-growth-trends-andforecast-2015-2020.html). In this way, there is an intense market to be explored not only to food industries as demonstrated but also to other segments such as pharmaceutical, chemistry, among others.

Natural colorant is, by definition, synthesized by and accumulated and/or excreted by living cells (Dabas et al. 2011). It can be extracted from plants, insects, microorganisms, animals, and minerals. They constitute a group of chemically heterogeneous and biosynthetically unrelated molecules that are united by a common feature: their electronic structure contains a chromophore that is responsible for the characteristic colors of these compounds (Pereira et al. 2014). Among them, five are considered as the most important in the global market: bixin, paprika, turmeric, anthocyanins, and cochineal carmine (Constant et al. 2002). However, there are several studies using microorganisms as producers of natural colorants, and efforts have been made in order to reduce the production costs of these compounds compared to synthetic colorants or colorants extracted from natural sources (Dufossé et al. 2014).

Furthermore, the use of fungi for producing colorants is increasing, since many ascomycetes naturally synthesize and secrete colorants and may be considered as a reliable source of natural organic colorants with improved functionality (Mapari et al. 2009a). The diversity of fungal colorants is because of the range of colors that they can produce in some cases with interesting properties such as antioxidant and antitumor characteristics (Mapari et al. 2009a). So, this review will explore the diversity of filamentous fungi producer of colorants, some aspects of their production process, and future applications.

\section{Natural colorants from microbial origin}

The production of biomolecules by microorganisms is related to the conditions of the bioprocess. It is important to find the best way to conduct the process and define the nutrient concentrations, not only to reduce production cost but also to increase the colorant production. Therefore, most studies in the literature focus on the improvement of production conditions (Velmurugan et al. 2010a, Hailei et al. 2012, Hu et al. 2012a, Arai et al. 2013, Santos-Ebinuma et al. 2013a, SantosEbinuma et al. 2014).

Natural colorants from microorganisms have production advantages compared with similar products extracted from plants or animals, since they do not exhibit the problem of 
seasonal availability and are often more stable and soluble (Gunasekaran and Poorniammal 2008). The synthesis of colorants by plant species is slower than that by microorganisms and algae, since the fermentation processes are inherently faster and more productive than other chemical processes (Velmurugan et al. 2010a).

For the industrial perspective, the colorants produced by microorganisms are relevant because it is possible to guarantee that the metabolite of interest will be produced under controlled conditions, regardless of external factors and seasonal supply of raw materials, and the batch-to-batch variability can be minimized (Mapari et al. 2010). Besides, there is a diversity of microorganisms in the tropical and subtropical regions which offers a promising variety of colorant compounds that may be used for different applications (Ventura et al. 2013).

Food industries from Europe and the USA have already obtained natural colorants from microorganisms due to their advantages such as stability, large-scale production, high growth rate, high throughput and wide range of colors and also due to their biological activities, such as antimicrobial, antioxidant, and anticancer properties (Mapari et al. 2009a; Pangestuti and Kim 2011; Teixeira et al. 2012; Tuli et al. 2014). The microorganisms produce a diversity of biocompounds, such as carotenoids, melanins, flavins, quinones, monascines, violaceins, phycocyanins, and indigo (Mapari et al. 2009a; Dufossé et al. 2014). Among the microorganisms, fungi play an important role as colorant producer. So, they will be the focus of this review. Table 1 shows some examples of natural colorants produced by filamentous fungi.

\section{Production process of natural colorants from fungi}

Fungi produce a large amount of secondary metabolites that are important for the industry, including the colorant industry. The colorants naturally produced by fungi can be considered as a reliable source of natural organic colorants with improved functionality (Mapari et al. 2009a). The diversity of fungal colorants is not only due to their chemical structure but also due to their range of colors, which may add new or additional hues to the color palette of the existing colorants arising from contemporary sources (Mapari et al. 2009a, Santos-Ebinuma et al. 2013b).

The colorants from fungi can be broadly classified chemically as carotenoids and polyketides (Mapari et al. 2010). Fungal polyketide pigments range in structure from tetraketides to octaketides, which have four or eight $C_{2}$ units that contribute to the polyketide chain. Representative classes include the anthraquinones, hydroxyanthraquinones, naphthoquinones, and azaphilone structures, each of which exhibits an array of color hues (Mapari et al. 2010). The structure of the polyketides does not exhibit localized negatively charged ions. These molecules often have polyunsaturated function, i.e., a ring system, one or more carbonyl groups, carbolic acid, and functional ester or amide groups that absorb in the UV-visible spectrum (Mapari et al. 2009a). Moreover, polyketides can be bioactive molecules, such as antibiotics, anticancer agents, immunosuppressors, antifungals, and cardiovascular agents (Mapari et al. 2009a).

The oldest colorant in use is angkak, also called red koji, from fermented rice by the fungus Monascus. In Europe, the first success story of colorant production by microorganisms was the fungus Blakeslea to produce $\beta$-carotene. Successful production of carotenoids has been achieved with two microalgae, namely $\beta$-carotene using Dunaliella and astaxantin using Haematococcus (Dufossé et al. 2005). Fungi Blakeslea trispora, Mucor circinelloides, and Phycomyces blakesleeanus are microorganisms that produce $\beta$-carotene colorant, which is a yellowish carotenoid colorant also known as pro-vitamin A (Kumar et al. 2015).

Fungi of the genus Monascus are known as great producers of natural colorants. The colorants produced by the species of Monascus are the most part azaphilone ones; the six major azaphilone colorants produced by Monascus species are monascin and ankaflavin (yellow colorants), monascorubrin and rubropunctain (orange colorants), and monascorubramine and rubropunctamine (red ones) (Frisvad et al. 2013). Among the genus Monascus, the species M. purpureus (Shi and Pan 2011; Prajapati et al. 2014) and M. ruber (Meinicke et al. 2012, Vendruscolo et al. 2013) are the most studied in terms of colorant production. Previous studies have shown that colorants produced by fungus of the genus Monascus exhibit biological activities, such as antimutagenic and anticancer properties, antimicrobial activity, potential anti-obesity activity (Feng et al. 2012), anti-inflammatory (Cheng et al. 2012), antioxidant activities (Hsu and Pan 2012) and as a dietary supplement to hyperlipidemia, ameliorate hypertension, and hypercholesterolemia (Lin et al. 2008). However, certain strains of Monascus have also been reported as co-producers of mycotoxin citrinin and other potentially toxic metabolites (Mapari et al. 2010) under certain conditions of cultivation (Lin et al. 2008). Despite of the efforts from several research groups to minimize the mycotoxin production, it is still present in the fermentation process, increasing the urge to find new producers.

Mapari et al. (2008) performed a screening of Talaromyces (formerly Penicillium) strains that are potential producers of natural colorants with a polyketide structure and chromophores similar to the Monascus colorants. The species under analysis were T. purpurogenus (formerly P. purpurogenum), T. pinophilus (formerly P. pinophilum), T. aculeatus (formerly P. aculeatum), T. funiculosus (formerly P. funiculosum), and $T$. minioluteus (formerly P. minioluteum). Among the produced metabolites, monascorubrin, xanthomonasin A, and derivatives of rubropunctatin were found in the extract of $T$. aculeatus (formerly P. aculeatum), and monascorubrin was 
Table 1 Examples of microbial colorants

\begin{tabular}{|c|c|c|}
\hline Molecule & Color & Microorganism \\
\hline Ankaflavin & Yellow & Monascus sp. \\
\hline \multirow[t]{2}{*}{ Antraquinone } & Red & Penicillium oxalicum \\
\hline & & Isaria farinosa (formerly Paecilomyces farinosus) \\
\hline \multirow[t]{5}{*}{$\beta$-Carotene } & Cream & Blakeslea trispora \\
\hline & Yellow-orange & Fusarium sporotrichioides \\
\hline & & Mucor circinelloides \\
\hline & & Neurospa crassa \\
\hline & & Phycomyces blakesleeanus \\
\hline Canthaxanthin & Orange-pink & Monascus roseus \\
\hline \multirow[t]{2}{*}{ Lycopene } & Red & Blakeslea trispora \\
\hline & & Fusarium sporotrichioides \\
\hline Monascin & Red-yellow & Monascus purpureus \\
\hline Monascorubramin & Red-orange & Monascus sp. \\
\hline Riboflavin & Yellow & Ashbya gossypii (also known as Eremothecium gossypii) \\
\hline Rubropunctatin & Orange & Monascus sp. \\
\hline \multirow[t]{6}{*}{ Unknown } & Orange-red & Aspergillus sp. \\
\hline & Dark-red & Aspergillus glaucus \\
\hline & Red & Talaromyces purpurogenus (formerly Penicillium purpurogenum) \\
\hline & & Isaria cicadae (formerly Paecilomyces sinclairii) \\
\hline & Orange & Penicillium cyclopium \\
\hline & Yellow & Penicillium nalgiovense \\
\hline
\end{tabular}

SOURCE: Dufossé 2006; Malik et al. 2012 identified in the extract of $T$. pinophilus (formerly $P$. pinophilum). None of the extracts contained citrinin. Figure 1 shows the chemical structure of some colorants produced by filamentous fungi. Later on, Mapari et al. (2009b) identified ten strains of fungi belonging to four species T. purpurogenus (formerly $P$. purpurogenum), T. aculeatus (formerly $P$. aculeatum), T. funiculosus (formerly P. funiculosum), and $T$. pinophilus (formerly P. pinophilum) as potential pigment producers that produce Monascus-like pigment but with no known mycotoxins.

Frisvad et al. (2013) also studied some Talaromyces species as producer of polyketide azaphilone Monascus red colorants: T. aculeatus, T. pinophilus, T. purpurogenus, T. funicolosus, $T$. atroroseus, T. amestolkiae, T. ruber, and T. funiculosus. These species did not produce citrinin; however, some strains can be human pathogens (T. amestolkiae and T. stollii) or producers of other class of mycotoxins such as rubratoxins A and B by $T$. purpurogenus (Frisvad et al. 2013).

Many colorants with non-carotenoid characteristics are produced by fungi, including quinones, dihydroxynaphthalene melanin (a complex aggregate of polyketides), and flavin components. From quinone class, the pigments anthraquinone and erioglaucine are produced by Eutotium spp., Fusarium spp., Curvularia lunata, and Drechslera spp. The first commercial product of the anthraquinone family was the colorant Arpink
$\operatorname{Red}^{\mathrm{TM}}$ (Natural Red ${ }^{\mathrm{TM}}$ ), produced by the company ASCOLOR BIOTECH, Czech Republic, by the fungal strain Penicillium oxalicum var. Armeniaca CCM 8242 (Dufossé et al. 2014).

Among the species of Penicillium, T. purpurogenus (formerly $P$. purpurogenum) produces colorants not only in solid medium but also in liquid (Méndez et al. 2011). In studies conducted by Teixeira et al. (2012), natural colorants produced by this strain exhibited significant antimicrobial activity and absence of toxicity against the microcrustacea Artemia salina. Figure 2 shows the reverse of the colony of $T$. purpurogenus (formerly P. purpurogenum) DPUA 1275 which secreted red colorants according the media used.

There are several submerged culture techniques involving microorganisms. In the batch procedure (also called discontinuous procedure), all the nutrients required for the culture, with the exception of oxygen in aerobic processes or chemical components for $\mathrm{pH}$ adjustment, are added before the start of the cultivation, and the product is only removed at the end of each procedure. In the continuous procedure, nutrients are added continuously, and the culture medium is removed at the same speed of the feeding flow, with the volume inside the bioreactor remaining constant (Schmidell et al. 2001). Furthermore, increasing the scale of submerged cultures for further industrial application requires maintaining the uniformity of various conditions of the process (temperature, $\mathrm{pH}$, 
Fig. 1 Chemical structure of some colorants produced by filamentous fungi (Mapari et al. 2008)

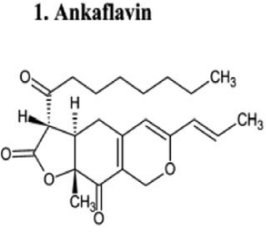

$\left(\mathrm{C}_{23} \mathrm{H}_{30} \mathrm{O}_{5}, 386.48\right)$

4. Rubropunctatin

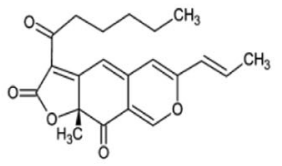

7. Xanthomonasin A

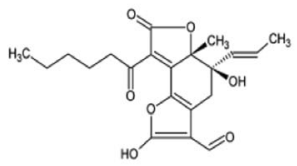

$\left(\mathrm{C}_{21} \mathrm{H}_{24} \mathrm{O}, 388.41\right)$
2. Monascin<smiles>C/C=C/C1=CC2=C(CO1)C(=O)[C@@]1(C)OC(=O)[C@H](C(=O)CCCCC)[C@]21C</smiles>

$\left(\mathrm{C}_{2 l} \mathrm{H}_{26} \mathrm{O}_{5}, 358.43\right)$

5. Rubropunctamine

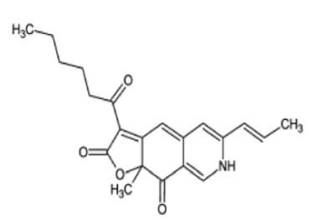

8. PP-V

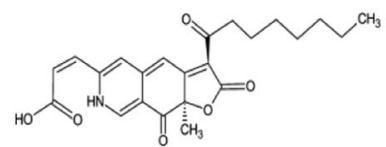

$\left(\mathrm{C}_{23} \mathrm{H}_{25} \mathrm{NO}_{6}, 411.45\right)$
3. Monascorubrin

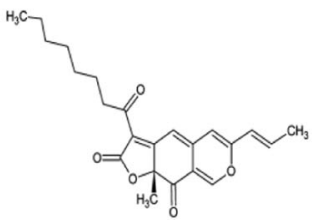

$\left(\mathrm{C}_{23} \mathrm{H}_{26} \mathrm{O}_{5}, 382.45\right)$

6. Monascorubramine<smiles>C/C=C/C1=CC2=C3C=C(C(=O)CCCCCCC)[C@@](C)(OC3=O)C(=O)C2=CN1</smiles>

B. Toxic metabolite Citrinin

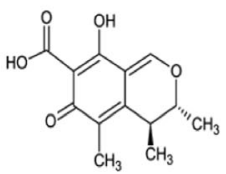

$\left(\mathrm{C}_{13} \mathrm{H}_{14} \mathrm{O}_{5}, 250.25\right)$ oxygen concentration, pressure, nutrient concentration, and shear stress), regardless of the volume of the bioreactor.

At bioreactor, the process of natural colorant production using filamentous fungi is a complex process that involves numerous variables, such as aeration rate, mass and heat transfer, and pH (Singh and Kaur 2014). In the submerged culture, the fungal morphology is usually divided into two types: individual filamentous mycelia and dense spherical colonies or pellets. The filamentous mycelia create a highly viscous and pseudoplastic culture medium, which reduces the gas-liquid mass transfer and the homogeneity in the bioreactor (Cui et al. 1998). Although the shape of the pellets generates a less viscous medium (Berovic et al. 1991), limited internal mass transfer can occur (Cui et al. 1998). In addition, the

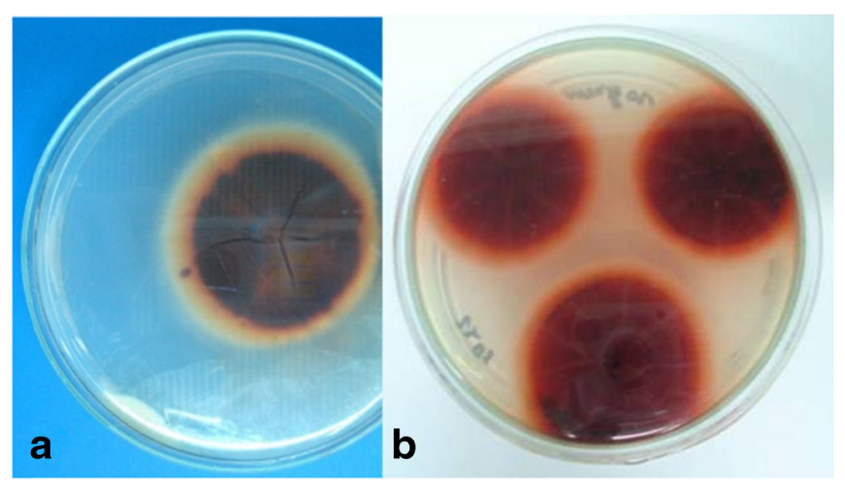

Fig. 2 Reverse of colony of $T$. purpurogenus (formerly $P$. purpurogenum) grown at Czapek Yeast Extract Agar-CYA (a), and agar potato dextrose-BDA (b) hydrodynamic conditions in the bioreactor, the tension of the dissolved oxygen, the fungal morphology and growth, the rheology of the medium, and the formation and secretion of products affect the bioprocess (Cui et al. 1998).

Therefore, the rheological characteristics of the liquid medium are affected by the submerged culture of filamentous fungi because of the changes in the composition of the substrate, the concentration of the biomass, and the morphology of microorganism (Cho et al. 2002a). The non-Newtonian behavior is an essential characteristic of the fungal submerged culture systems, in which either filaments or mycelia can predominate. At high microbial concentrations, the hypha can become entangled, resulting in a highly viscous suspension with a non-Newtonian behavior. Many studies have demonstrated that a culture medium containing high concentrations of filamentous microorganisms is highly viscous and is characterized by a shear rate that depends on viscosity and by drainage tension (Cho et al. 2002b). However, the production of natural colorants by fungi has been performed by many authors. Table 2 presents some works found in the literature showing the microorganism and colorant production. It can be observed that the red colorants are the most studied because of its high potential to be applied industrially. Following the works are described in more detail, mainly the production methodology used.

Cho et al. (2002a) studied the influence of the carbon source and the aeration rate on the rheology of the fermentation broth and the mycelial morphology; they also investigated the production of red pigments by Isaria cicadae (formerly Paecilomyces sinclairii) in a stirred tank-type bioreactor. It 
Table 2 Summary of works presented showing microorganism and production of colorants

\begin{tabular}{|c|c|c|c|}
\hline Colorant & Colorant production & Microorganism & Reference \\
\hline Red pigments & $4.73 \mathrm{~g} / \mathrm{L}$ in a stirRed tank-type bioreactor & $\begin{array}{l}\text { Isaria cicadae } \\
\quad \text { (formerly Paecilomyces sinclairii) }\end{array}$ & Cho et al. (2002a) \\
\hline Red pigments & $4.4 \mathrm{~g} / \mathrm{L}$ in 5 - $\mathrm{L}$ batch fermenter & $\begin{array}{l}\text { Isaria cicadae } \\
\quad \text { (formerly Paecilomyces sinclairii) }\end{array}$ & Cho et al. (2002b) \\
\hline Red pigment & $\begin{array}{l}2.75 \mathrm{~g} / \mathrm{L} \text { in shaker and } \\
7.7 \mathrm{~g} / \mathrm{L} \text { in a } 15-\mathrm{L} \text { bioreactor }\end{array}$ & $\begin{array}{l}\text { Candida tropicalis } \\
\quad \text { with Penicillium sp. HSD07B }\end{array}$ & Hailei et al. (2011) \\
\hline Not described & $36.75 \mathrm{OD} / \mathrm{g}^{\mathrm{a}}$ & Monascus purpureus & Velmurugan et al. (2010a) \\
\hline Red pigment & $\begin{array}{l}\text { In orbital shaker was } \\
4.25 \text { and } 6.40 \mathrm{~g} / \mathrm{L} \text { in batch reactor }\end{array}$ & P. novae-zeelandiae & Hailei et al. (2012) \\
\hline Red pigment & $2.46 \mathrm{~g} / \mathrm{L}$ in orbital shaker & $\begin{array}{l}\text { T. purpurogenus } \\
\text { (formerly Penicillium purpurogenum) }\end{array}$ & Mendez et al. (2011) \\
\hline Red pigments & $7.38 \mathrm{UA}_{480 \mathrm{~nm}}$ in rotary shaker ${ }^{\mathrm{a}}$ & Monascus ruber & Meinicke et al. (2012) \\
\hline Red pigments & 7.18 ODU $/ \mathrm{mL}$ in rotary shaker ${ }^{\mathrm{a}}$ & Monascus purpureus & Sharmila et al. (2013) \\
\hline $\begin{array}{l}\text { Violet pigment PP-V } \\
{[(10 Z)-12 \text {-carboxyl- }} \\
\text { monascorubramine }]\end{array}$ & $-{ }^{\mathrm{b}}$ & $\begin{array}{l}\text { T. purpurogenus } \\
\quad \text { (formerly P. purpurogenum) }\end{array}$ & Arai et al. (2013) \\
\hline Red pigment & $14.5 \mathrm{U} / \mathrm{mL}$ in rotary shaker ${ }^{\mathrm{a}}$ & Monascus purpureus & Prajapati et al. (2014) \\
\hline Red colorants & $3.19 \mathrm{UA}_{490 \mathrm{~nm}}$ in rotary shaker ${ }^{\mathrm{a}}$ & $\begin{array}{l}\text { T. purpurogenus } \\
\text { (formerly Penicillium purpurogenum) }\end{array}$ & Santos-Ebinuma et al. (2013a) \\
\hline Red colorants & $2.04 \mathrm{UA}_{490 \mathrm{~nm}}$ in rotary shaker ${ }^{\mathrm{a}}$ & $\begin{array}{l}\text { T. purpurogenus } \\
\text { (formerly Penicillium purpurogenum) }\end{array}$ & Santos-Ebinuma et al. (2014) \\
\hline Red pigment & $\begin{array}{l}20.44 \mathrm{abs}, 500 \mathrm{~nm} / \mathrm{mg} \text { dry fungal biomass } \\
\text { in orbital shaker }\end{array}$ & Monascus purpureus & Singh et al. (2015) \\
\hline Red pigments & $96 \mathrm{mg} / \mathrm{L}$ in fed-batch bioreactor & Monascus ruber & Hajjaj et al. (2015) \\
\hline
\end{tabular}

was observed that the specific production rate of the colorant was higher in the medium containing starch. The maximum production of red pigment, $4.73 \mathrm{~g} / \mathrm{L}$, was achieved with aeration rate of $3.5 \mathrm{vvm}$ (volume of air per volume of liquid per minute).

Cho et al. (2002b) studied the optimization of culture conditions for colorant production by $I$. cicadae (formerly $P$. sinclairii). They concluded that peptone meat gave higher yield of the colorant production. When performed in a bioreactor batch, production increased almost nine times the production in bioreactor achieving a production of $4.4 \mathrm{~g} / \mathrm{L}$ of red colorants in a 5 -L batch fermenter.

Hailei et al. (2011) cultivated Candida tropicalis with Penicillium sp. HSD07B and observed the production of a non-toxic and non-mutagenic red colorant. This colorant was stable at $\mathrm{pH} 2$ to 10 and temperatures of $10-100^{\circ} \mathrm{C}$. In addition, the colorant proved to be resistant to oxidation by hydrogen peroxide and to reduction by sodium sulfite, and also a good photostability. Under optimized conditions, the colorant production was of $2.75 \mathrm{~g} / \mathrm{L}$ in a shaker and $7.7 \mathrm{~g} / \mathrm{L}$ in a $15-\mathrm{L}$ bioreactor.

Given the high cost of production of red colorant, due to the complexity of the junction of cultures, later on Hailei et al. (2012) studied the production of red colorant through self immobilization from the biomembrane, formed on the surface of the liquid culture of Penicillium novae-zeelandiae. Statistical analysis showed that the concentration of glucose and the diameter of the membrane are the factors that influence colorant production. The strain growth occurred in three phases, wherein the colorant is secreted initially within the membrane, in the deceleration phase, whereby the exhaustion of glucose occurred. After optimization, the maximum red colorant production in orbital shaker was $4.25 \mathrm{~g} / \mathrm{L}$ and it was found that production increased $61.5 \%$ when subjected to a continuous reactor.

The same authors (Hailei et al. 2012) investigated the mechanism induction of red colorant production in the coculture and developed a process for the production of it in a pure culture. It was observed that the exhaustion of the first carbon source is the fundamental reason for the production of colorant. Candida tropicalis converts glucose to glycerol, ethanol, organic acids, and other substances resulting in the depletion of glucose and secretion of the pigment. The new system of cultivation was the eutrophic-oligotrophic, developed to produce the red colorant during the monoculture of Penicillium sp. HSD07B. Although some of pigment components from the monoculture have appeared only with the supply of glycerol, it showed an increase in the production of the 
same. Therefore, it was noted that the glucose metabolite accumulation is an important factor in red pigment production in co-culture.

Santos-Ebinuma et al. (2013a) optimized the production of red colorants by $T$. purpurogenus (formerly $P$. purpurogenum), increasing the production by $78 \%$ using statistical tool. To evaluate the stability of colorants, the authors studied several conditions: $\mathrm{pH}$, temperature, and the presence of salts or polymers. The best conditions were $\mathrm{pH} 8.0$ and $70{ }^{\circ} \mathrm{C}$; the colorant also showed good stability in the presence of the salts $\mathrm{NaCl}$ and $\mathrm{Na}_{2} \mathrm{SO}_{4}$ and the polymers polyethylene glycol and sodium polyacrylate.

In another study, Santos-Ebinuma et al. (2014) investigated the production of natural colorants yellow, orange, and red in submerged culture of $T$. purpurogenus (formerly $P$. purpurogenum). Different conditions were evaluated as follows: the effect of incubation time, type and size of the inoculum, and different sources of carbon and nitrogen. The authors obtained the best kinetics growing for all three colorants under conditions of five agar discs with mycelia at $336 \mathrm{~h}$ of fermentation. In addition, the most suitable sources of carbon and nitrogen were sucrose and yeast extract, respectively.

Arai et al. (2013) investigated the importance of assimilation of ammonia in the production of amino derivative colorants homologous from Monascus by T. purpurogenus (formerly P. purpurogenum) (PP-V). They also investigated the expression of glutamine synthetase $(\mathrm{g} \ln \mathrm{B})$ and glutamine dehydrogenase (gdh1), two enzymes associated with the conversion of nitrate or nitrite to amino acids and inhibition of the pigment production using L-methionine-DL-sulfoximine (MSX). The genes of gdh1 and $g \ln B$ were expressed in the $\mathrm{PP}-\mathrm{V}$ production conditions, and the glnB expression was slightly higher. PP-V biosynthesis was more efficient with Gln use as a nitrogen source than with the use of Glu. With the addition of MSX in half the amount of PP-V decreases markedly. Finally, it is concluded that the ammonia synthesis Gln glutamine synthetase is important for the production of PP-V.

In order to optimize the production of pigments by $M$. ruber, Meinicke et al. (2012) used culture media containing glycerol as a carbon source and monosodium glutamate (MSG) as a nitrogen source. It was found that both the concentrations of MSG and glycerol are important factors, but the concentration of MSG is the most significant variable in the production of the colorant. The best production of red colorants was obtained between 40-70 g/L glycerol and 7-9 g/L MSG. Moreover, it is noted that it is possible to use waste glycerol from biodiesel production for colorants.

Sharmila et al. (2013) examined variables and optimized the production of red pigments by $M$. purpureus by using potato powder as an alternative source of carbon. The maximum absorbance of the pigment was $7.18 \mathrm{ODU} / \mathrm{mL}$ and was foreseen for an optimum of potato powder of $2.5 \%(w / v), 0.48 \%(w / v) \mathrm{K}_{2} \mathrm{HPO}_{4}$, and $0.60 \%(w / v)$ MSG. They concluded that potato powder can be used as a substrate for low-cost production of red colorant on a large scale.

In study performed by $\mathrm{Hu}$ et al. (2012b) the perstractive fermentation of intracellular colorants produced by Monascus in aqueous non-ionic surfactant Triton X-100 was examined, in which intracellular products were transported to the extracellular micelles in aqueous solution of non-ionic surfactants. It was noted that the relatively low density of the colorant in the microbial cells eliminates the inhibition of the product and prevents it from being degraded. Kang et al. (2013) examined the effects of $\mathrm{pH}$ and non-ionic surfactant in the profile of intra- and extracellular Monascus colorants. Results showed that extracellular $\mathrm{pH}$ influences the absorption of MSG and the exportation of water-soluble red pigment during fermentation of Monascus. Regarding the effect of the non-ionic surfactant, it was found that the export of hydrophobic colorants was affected by intracellular perstractive fermentation and independent of $\mathrm{pH}$. In this fermentation, the production of red and yellow colorants extracellular was higher when the initial $\mathrm{pH}$ were, respectively, higher and lower.

Mendez et al. (2011) studied the effect of temperature and $\mathrm{pH}$ on the production of red colorants by $T$. purpurogenus (formerly $P$. purpurogenum) in submerged culture. It was observed that maximum production of red pigment $(2.46 \mathrm{~g} / \mathrm{L})$ was obtained at $\mathrm{pH} 5$ and $34{ }^{\circ} \mathrm{C}$, and the maximum concentration of biomass was obtained at pH 7 and $34{ }^{\circ} \mathrm{C}$. From these results, it was found that there is a direct relationship between the production of colorant and biomass concentration. Furthermore, the maximum pigment production was associated with strong combination of $\mathrm{pH}$ and temperature effects.

Prajapati et al. (2014) studied the increase in the production of red colorant by submerged culture of $M$. purpureus through optimization. The results indicated that glucose, tryptone, and $\mathrm{pH}$ of the medium are highly important in colorant production. Moreover, unlike other researchers reported, in this study, the best nitrogen source is tryptone, instead of MSG. The maximum production of the colorant (OD $14.5 \mathrm{U} / \mathrm{mL}$ ) was achieved with $58 \mathrm{~g} / \mathrm{L}$ glucose, $1 \mathrm{~g} / \mathrm{L}$ tryptone, and $\mathrm{pH} 8$.

Singh et al. (2015) investigated the application of artificial neural network (ANN) in modeling a liquid state fermentation for red colorant production by $M$. purpureus MTCC 369 using rice water base medium. They concluded that rice water medium is an effective substrate for producing the red colorant without any external nitrogen source and, also, that the ANN analysis provides a dynamic model for successful prediction of optimal operating conditions. 
Hamano et al. (2005) showed that the specific production of extracellular red colorant by different strains of Monascus sp. is 1.7-3.5 higher than the specific production of intracellular red colorant in semi-synthetic medium on a rotary shaker.

Mukherjee and Singh (2011) purified and characterized a new red colorant from $M$. purpureus in submerged fermentation. The colorant was extracted using hexane and purified by thin layer chromatography, column chromatography, and semi-preparative HPLC. By UV-vis, IR, GC-MS, and NMR analyses, the pigment was characterized as 9-(1-hydroxyhexyl)-3-(2-hydroxypropyl)-6a-methyl-9,9a-dihydrofuro[2,3-h] isoquinoline-6, $8(2 H, 6 \mathrm{a} H)$-dione; this colorant presented similarities with rubropunctamine and monascorubramine, but it presented an hydroxyl alkane substitutions at C-3 and C-9 position. This colorant also showed antibacterial activity against Gram-positive bacteria. The authors indicate that in higher $\mathrm{pH}$, consolidation of red colorant production was observed and found that $18 \mathrm{gl} / \mathrm{L}$ of glucose is optimum for red colorant production.

Velmurugan et al. (2010a) studied the effects of total darkness and different shades of light in the extra- and intracellular production of colorants and biomass of five fungi: M. purpureus, Isaria farinosa, Emericella nidulans, Fusarium verticillioides, and T. purpurogenus (formerly $P$. purpurogenum). It was noted that in all fungi, incubation in the dark increased biomass and colorant production. In addition, it was concluded that in all of them, there is no effect on growth under red light, and under green or yellow light, the growth decreases. Maximum production of extra- and intracellular red colorants by $M$. purpureus occurred in the dark and was, respectively, 36.75 and $18.27 \mathrm{OD} / \mathrm{g}$.

Hajjaj et al. (2015) focused on the influence of nitrogen/carbon ratio and mode of cultivation on the production of red colorants and citrinin in M. ruber. Using monosodium glutamate and glucose, they confirmed that the max production of red colorant was at a ratio around 10 of $\mathrm{C} / \mathrm{N}$; citrin production increased with the increase of the $\mathrm{C} / \mathrm{N}$ ratio. They showed, too, that the successive feed of glucose with low $\mathrm{C} / \mathrm{N}$ ratio induced the accumulation of L-malic acid, which is unfavorable for red colorant production.

Velmurugan et al. (2011) investigated the production of red colorants by M. purpureus using corn cob powder as a substrate for solid-state fermentation. The higher production of pigment was $25.42 \mathrm{OD} / \mathrm{g}$ after 7 days of incubation at $30{ }^{\circ} \mathrm{C}$, and inoculated with $4 \mathrm{~mL}$ spores $/ \mathrm{g}$ and initial moisture content of $60 \%$. The pigments are stable in acidic $\mathrm{pH}$, at high temperature, and in saline solutions. It was found that the production of colorants using corn cob powder is much higher than with the use of other agricultural waste.

\section{Application of natural colorants}

Natural colorants are widely used in the textile (Islam et al. 2013), paper (Malik et al. 2012), leather (Guillén et al. 2012), and timber industries (Ali, 2010). Foods are often colored with natural or synthetic colorants approved by a regulatory agency (Carocho et al. 2014). It is also used to provide color to petroleum derivates, such as waxes, lubricant oils, ointments, and gasoline; plastics; resins; and rubber products (Kumari et al. 2012). One of the important issues in the application of colorants is safety, so there are many limitations and legislation on the use of dyes in different countries (Nikfar and Jaberidoost, 2014).

Also, there is an increasing demand for natural non-toxic and/or eco-friendly colorants on industry, particularly those to be applied in the healthcare area, food, children's toys, and leather elements (Velmurugan et al. 2010b).

It is hard to estimate the market for natural colorants produced by bioprocess, although there is an increasing preference for the use of natural additives in food and cosmetic products. According to Mapari et al. (2010), natural colorants accounted for $31 \%$ of the colorants market, whereas synthetic colorants made up $40 \%$ and nature-identical colorants accounted for $29 \%$ of the market. In addition, the Leatherhead Food International points out that the natural colorants market is growing and that these products will replace synthetic colorants in the future. In 2007, the colorants market in the food sector was estimated at USD 1.15 billion, a $2.5 \%$ increase compared to 2004 (USD 1.07 billion); from this, USD 465 million was from natural colorants, a $4.6 \%$ increase compared to 2004 (Mapari et al. 2010).

Natural colorants derived from algae or extracted from flowering plants have been used in food and nutritional supplements showing the importance of niche markets in which consumers are willing to pay a premium for "natural healthy ingredients" (Dufossé et al. 2014). In the pharmaceutical industry, the colorants produced by filamentous fungi can be interesting because they can not only promote color but also have potential clinical application since they can act as anticancer, antiproliferative, antibiotics, etc. In the textile area, the use of non-allergic, non-toxic, and eco-friendly natural colorants has increased due to environmental awareness in order to avoid some synthetic colorants with hazardous characteristics (Samanta and Agarwal 2009).

Velmurugan et al. (2010b) studied the dyeing potential of five different water-soluble colorants extracted from $M$. purpureus, Isaria spp., Emericella spp., Fusarium spp., and Penicillium spp. The authors optimized the dyeing process in leather resulting in uniform dyeing and intense and bright shade. According to the authors, the results obtained indicated that the fungal colorants could be an alternate for leather dyeing as a natural dye. 
Some species of filamentous fungi such as $P$. oxalicum and Monascus species, which produce colorants that have been used as food colorants for hundreds of years in the Far East, Phaffia rohodozoa, Ashbya gossypii, and Blaskelea trispora are in the stage of industrial production. However, the most part of natural colorants produced by fungus is at development or research stage, and in order to obtain success in the application of these natural colorants, the approval of their application by the regulatory agencies is essential. In this way, there is a vast field of study to be explored involving new producing species and new molecules with biological activity and without the associated production of mycotoxins and studies of toxicity.

\section{Conclusion}

Since the health-conscious consumer has had an upward growth, the natural colorant application has been increasing in the last years in different industries from food until textile coloration. For this reason, the natural colorants produced by microorganisms have been deeply studied. Although Monascus is the more studied specie, other filamentous fungi have been evaluated resulting in colorants with diversified chemical structure, properties, and applications. This review has highlighted studies that utilized different filamentous fungi species to produce high yields of the natural colorants, indicating the biological activity and its application. However, there is a lack of deeper studies of the use of bioreactors for natural colorant production, as well as their toxicology studies, which are necessary to the industrialization and introduction of these biotechnological products on the market.

Acknowledgments This research was supported by grants from the Coordination for Higher Level Graduate Improvements (CAPES/Brazil), National Council for Scientific and Technological Development (CNPq/Brazil), State of São Paulo Research Foundation (FAPESP/ Brazil, Process number 2014/01580-3), and Development Support Programme Science of Pharmaceutical Sciences College of UNESP Araraquara (PADC, Process number 22/2014).

\section{Compliance with ethical standards}

Ethical statement The authors, whose names appear on the submission, declare that they have contributed sufficiently to the scientific work and therefore share collective responsibility and accountability for the results. This manuscript has not been published or presented elsewhere in part or in entirety and is not under consideration by another journal. This research does not involve human participants or animals.

All the authors have approved the manuscript and agree with submission to your esteemed journal.

Conflict of interest The authors declare that they have no competing interests.

\section{References}

Ali H (2010) Biodegradation of synthetic dyes - a review. Water Air Soil Poll 2013:251-273. doi:10.1007/s11270-010-0382-4

Arai T, Koganei K, Umemura S, Kojima R, Kato J, Kasumi T, Ogihara J (2013) Importance of the ammonia assimilation by Penicillium purpurogenum in amino derivative Monascus pigment, $\mathrm{PP}-\mathrm{V}$, production. AMB Express 3:19. doi:10.1186/2191-0855-3-19

Barnett JR, Miller S, Pearce E (2006) Colour and art: a brief history of pigments. Opt Laser Technol 38:445-453. doi:10.1016/j.optlastec. 2005.06.005

Bechtold T, Mussak R. (2009) Front Matter, in Handbook of natural colorants. John Wiley \& Sons, Ltd, Chichester, UK. doi:10.1002/ 9780470744970.fmatter

Berovic M, Cimerman A, Steiner W, Koloin T (1991) Submerged citric acid fermentation: rheological properties of Aspergillus niger broth in a stirred tank reactor. Appl Microbiol Biotechnol 34:579-581. doi:10.1007/BF00167902

Cañamares MV, Lombardi JR (2015) Raman, SERS, and DFT of mauve dye: adsorption on Ag nanoparticles. J Phys Chem C 119:1429714303. doi:10.1021/acs.jpcc.5b02619

Carocho M, Barreiro MF, Morales P, Ferreira ICFR (2014) Adding molecules to food, pros and cons: a review of synthetic and natural food additives. Compr Rev Food Sci F 13:377-399. doi:10.1111/15414337.12065

Cheng MJ, Wua MD, Yuan GF, Su YS, Yanai H (2012) Secondary metabolites produced by the fungus Monascus pilosus and their antiinflamatory activity. Phytochem Lett 5:567-571. doi:10.1016/j. phytol.2012.05.015

Cho YJ, Hwang HJ, Kim SW, Song CH, Yun JW (2002a) Effect of carbon source and aeration rate on broth rheology and fungal morphology during red pigment production by Paecilomyces sinclairii in a batch bioreactor. J Biotech 95:13-23. doi:10.1016/S01681656(01)00445-X

Cho YJ, Park JP, Hwang HJ, Kim SW, Choi JW, Yun JW (2002b) Production of red pigment by submerged culture of Paecilomyces sinclairii. Lett Appl Microbiol 35:195-202. doi:10.1046/j.1472765X.2002.01168.X

Constant PBL, Strungheta PC, Sandi D (2002) Corantes alimentícios. Bol Centro Pesqui Process Aliment 20:203-220. doi:10.5380/cep.v20i2. 1248

Cui YQ, Van der Lans RG, Luyben KC (1998) Effects of dissolved oxygen tension and mechanical forces on fungal morphology in submerged fermentation. Biotechnol Bioeng. 57:409-419. doi:10. 1002/(SICI)1097-0290(19980220)

Dabas D, Elias RJ, Lambert JD, Ziegler GR (2011) A colored avocado seed extract as a potential natural colorant. J Food Sci 76:13351341. doi:10.1111/j.1750-3841.2011.02415.x

Dufossé L, Fouillaud M, Caro Y, Mapari SAS, Sutthiwong N (2014) Filamentous fungi are large-scale producers of pigments and colorants for the food industry. Curr Opin Biotechnol 56:56-61. doi:10. 1016/j.copbio.2013.09.007

Dufossé L (2006) Microbial production of food grade pigments. Food Tech Biotechnol 44:313-321. doi:10.1016/j.copbio.2013.09.007

Dufossé L, Galaup P, Yaron A, Arad SM, Blanc P, Murthy KNC, Ravishankar GA (2005) Microorganisms and microalgae as sources of pigments for food use: a scientific oddity or an industrial reality? Trends Food Sci Tech 16:389-406. doi:10.1016/j.tifs.2005.02.006

Feng Y, Shao Y, Chen F (2012) Monascus pigments. Appl Microbiol Biotechnol 96:1421-1440. doi:10.1007/s00253-012-4504-3

Fernández-Lopez JA, Angosto JM, Giménez PJ, León G (2013) Thermal stability of selected natural red extracts used as food colorants. Plant Foods Hum Nutr 68:11-17. doi:10.1007/s11130-013-0337-1

Frisvad JC, Yilmaz N, Thrane U, Rasmussen KB, Houbraken J, Samson RA (2013) Talaromyces atroroseus, a new species efficiently 
producing industrially relevant red pigments. PlosONE 8:e84102. doi:10.1371/journal.pone.0084102

Guillén D, Ginebreda A, Petrovic M, Barceló D, Darbra RM, Rydin S (2012) Global risk-based management of chemical additives I. The handbook of environmental chemistry. Springer, London

Gunasekaran S, Poorniammal R (2008) Optimization of fermentation conditions for red pigment production from Penicillium $\mathrm{sp}$. under submerged cultivation. Afr J Biotechnol 7:1894-1898. doi:10.1111/ jam. 12110

Hailei W, Ping L, Yufeng L, Zhifang R, Gang W (2012) Overproduction of a potential red pigment by a specific self-immobilization biomembrane-surface liquid culture of Penicillium novae-zeelandiae. Bioproc Biosyst Eng 35:1407-1416. doi:10.1007/s00449-0120729-x

Hailei W, Zhifang R, Ping L, Yanchang G, Guosheng L, Jianming Y (2011) Improvement of the production of a red pigment in Penicillium sp. HSD07B synthesized during co-culture with Candida tropicalis. Bioresource Technol 102:6082-6087. doi:10. 1016/j.biortech.2011.01.040

Hajjaj H, Goma G, François JM (2015) Effect of the cultivation mode on red pigments production from Monascus ruber. Int J Food Sci Tech 50:1731-1736. doi:10.1111/ijfs. 12803

Hamano PS, Orozco SFB, Kilikian BV (2005) Concentration determination of extracelular and intracellular red pigments produced by Monascus sp. Braz Arch Biol Technol 48:43-49. doi:10.1590/ S1516-89132005000400006

Hill DJ (1997) Is there a future for natural dyes? Rev Prog Color 27:18 25. doi:10.1111/j.1478-4408.1997.tb03771.x

Hsu WH, Pan TM (2012) Monascus purpureus fermented products and oral cancer: a review. Appl Microbiol Biotechnol 93:1831-1842. doi:10.1007/s00253-012-3891-9

Hu Z, Zhang X, Wu Z, Qi H, Wang Z (2012a) Perstraction of intracellular pigments by submerged cultivation of Monascus in nonionic surfactant micelle aqueous solution. Appl Microbiol Biotechno. 94:81-89. doi:10.1007/s00253-011-3851-9

Hu Z, Zhang X, Wu Z, Qi H, Wang Z (2012b) Export of intracellular Monascus pigments by two-stage microbial fermentation in nonionic surfactant micelle aqueous solution. J Biotechnol 162:202-209. doi:10.1016/j.jbiotec.2012.10.004

Islam S, Shahid M, Mohammad F (2013) Perspectives for natural products based agents derived from industrial plants in textile applications - a review. J Clean Prod 57:2-18. doi:10.1016/j.jclepro.2013. 06.004

Kang B, Zhang X, Wu Z, Qi H, Wang Z (2013) Effect of pH and nonionic surfactant on profile of intracellular and extracellular Monascus pigment. Process Biochem 48:759-767. doi:10.1016/j.procbio.2013. 03.020

Kumari LS, Rao PP, Sameera S, Koshy P (2012) Synthesis and optical properties of $\mathrm{Ce}_{0.95} \mathrm{Pr}_{0.05-\mathrm{x}} \mathrm{M}_{\mathrm{x}} \mathrm{O}_{2}(\mathrm{M}=\mathrm{Mn}, \mathrm{Si})$ as potential ecological red pigments for coloration of plastics. Ceram Int 38:40094016. doi:10.1016/j.ceramint.2012.01.057

Kumar A, Vishwakarma HS, Singh J, Dwivedi S, Kumar M (2015) Microbial pigments: production and their applications in various industries. Int J Pharm Chem Biol Sci 5:203-212

Lin YL, Wang TH, Lee MH (2008) Biologically active components and nutraceuticals in the Monascus-fermented rice: a review. Appl Microbiol Biotechnol 77:965-973. doi:10. 1007/s00253-007-1256-6

Malik K, Tokka J, Goyal S (2012) Microbial pigments: a review. International J Microbial Resource Technol 1(4):361-365

Mapari SAS, Hansen ME, Meyer AS, Thrane U (2008) Computerized screening for novel producers of Monascus-like food pigments in Penicillium species. J Agric Food Chem 56:9981-9989. doi:10. $1021 / \mathrm{jf} 801817 \mathrm{q}$
Mapari SAS, Meyer AS, Thrane U (2009a) Photostability of natural orange-red and yellow fungal pigments in liquid food model systems. J Agr Food Chem 57:6253-6261. doi:10.1021/jf900113q

Mapari SAS, Meyer AS, Thrane U, Frisvad JC (2009b) Identification of potentially safe promising fungal cell factories for the production of polyketide natural food colorants using chemotaxonomic rationale. Microb Cell Factories 8:24. doi:10.1186/1475-2859-8-24

Mapari SAS, Thrane U, Meyer AS (2010) Fungal polyketide azaphilone pigments as future natural food colorants? Trends Biotechnol 28: 300-307. doi:10.1016/j.tibtech.2010.03.004

Masone D, Chanforan C (2015) Study on the interaction of artificial and natural food colorants with human serum albumin: a computational point of view. Comput Biol Chem 56:152-158. doi:10.1016/j. compbiolchem.2015.04.006

Medeiros RA, Lourençao BC, Rocha-Filho RC, Fatibello-Filho O (2012) Simultaneous voltammetric determination of synthetic colorants in food using a cathodically pretreated boron-doped diamond electrode. Talanta 97:291-297. doi:10.1016/j.talanta.2012.04.033

Meinicke RM, Vendruscolo F, Esteves Moritz D, Oliveira D, Schmidell W, Samohyl RW, Ninow JL (2012) Potential use of glycerol as substrate for the production of red pigments by Monascus ruber in submerged fermentation. Biocatal Agric Biotechnol 1:238-242. doi: 10.1016/j.bcab.2012.03.001

Méndez A, Pérez C, Montañéz JC, Martínez G, Aguilar CN (2011) Red pigment production by Penicillium purpurogenum $\mathrm{GH} 2$ is influenced by $\mathrm{pH}$ and temperature. J Zhejiang Univ Sci B 12:961-968. doi:10.1631/jzus.B1100039

Mirjalili M, Nazarpoor K, Karimi L (2011) Eco-friendly dyeing of wool using natural dye from weld as co-partner with synthetic dye. J Clean Prod 19:1045-1051. doi:10.1016/j.jclepro.2011.02.001

Mukherjee G, Singh SK (2011) Purification and characterization of a new red pigment from Monascus purpureus in submerged fermentation. Proc Biochem 46:188-192. doi:10.1016/j.procbio.2010.08.006

Nikfar S, Jaberidoost M (2014) Dyes and Colorants. Reference Module in Biomedical Sciences. Encyclopedia of Toxicology, third edition, Elsevier, p. 252-261

Pan Y, Zhu Z, Huang Z, Wang H, Liang Y, Wang K, Lei Q, Liang M (2009) Characterisation and free radical scavenging activities of novel red pigment from Osmanthus fragrans' seeds. Food Chem 112:909-913. doi:10.1016/j.foodchem.2008.06.077

Pangestuti R, Kim SK (2011) Biological activities and health benefit effects of natural pigments derived from marine algae. J Func Foods 3:2255-2266. doi:10.1016/j.jff.2011.07.001

Patel SK, Saurabh KK, Kamlesh K, Mali MD (2012) Studies on synthesis of novel low molecular weight anthraquinone disperse dyes and their application on polyester and nylon. J Ind Chem Soc 89:789795

Pereira DN, Valentão P, Andrade PB (2014) Marine natural pigments: chemistry, distribution and analysis. Dyes Pigments 111:124-134. doi:10.1016/j.dyepig.2014.06.011

Prajapati VS, Soni N, Trivedi UB, Patel KC (2014) An enhancement of red pigment production by submerged culture of Monascus purpureus MTCC 410 employing statistical methodology. Biocatal Agric Biotechnol 3:140-145. doi:10.1016/j.bcab.2013.08.008

Rymbai H, Sharma RR, Srivastav M (2011) Biocolorants and its implications in health and food industry - a review. Int J PharmTech Res 3:2228-2244

Samanta AK, Agarwal P (2009) Application of natural dyes on textiles. Indian J Fibre Text 34:384-399.

Santos-Ebinuma VC, Roberto IC, Teixeira MFS, Pessoa A (2014) Improvement of submerged culture conditions to produce colorants by Penicillium purpurogenum. Braz J Microbiol 45:731-742. doi: 10.1590/S1517-83822014000200049

Santos-Ebinuma VC, Roberto IC, Teixeira MFS, Pessoa A (2013a) Improving of red colorants production by a new Penicillium purpurogenum strain in submerged culture and the effect of different 
parameters in their stability. Biotechnol Prog 29:778-785. doi:10. 1002/btpr. 1720

Santos-Ebinuma VC, Texeira MFS, Pessoa A (2013b) Submerged culture conditions for the production of alternative natural colorant by a new isolated Penicillium purpurogenum DPUA 1275. J Microbiol Biotechnol 23:802-810. doi:10.4014/jmb.1211.11057

Saron C, Felisberti MI (2006) Ação de colorantes na degradação e estabilização de polímeros. Quím Nov. 29:124-128. doi:10.1590/ S0100-40422006000100022

Sharmila G, Nidhi B, Muthukumaran C (2013) Sequential statistical optimization of red pigment production by Monascus purpureus (MTCC 369) using potato powder. Ind Crop Prod 44:158-164. doi:10.1016/j.indcrop.2012.11.007

Schmidell W, Lima AU, Aquarone E, Borzani W (2001) Biotecnologia Industrial. Blücher, São Paulo

Shi YC, Pan TZ (2011) Beneficial effects of Monascus purpureus NTU568-fermented products: a review. Appl Microbiol Biotechnol 90:1207-1217. doi:10.1007/s00253-011-3202-x

Singh N, Goel G, Singh N, Pathak BK, Kaushik D (2015) Modeling the red pigment production by Monascus purpureus MTCC 369 by artificial neural network using rice water based medium. Food Bioscience II 11:17-22. doi:10.1016/j.fbio.2015.04.001

Singh D, Kaur G (2014) Swainsonine, a novel fungal metabolite: optimization of fermentative production and bioreactor operations using evolutionary programming. Bioproc Biosyst Eng 37:1599-1607. doi:10.1007/s00449-014-1132-6

Sivakumar V, Vijaeeswarri J, Anna JL (2011) Effective natural dye from different plant materials using ultrasound. Ind Crop Prod 33:116 122. doi:10.1016/j.indcrop.2010.09.007

Sousa MM, Melo MJ, Parola AJ, Morris PJ, Rzepa HS, de Melo JS (2008) A study in mauve: unveiling Perkin's dye in historic sample. Chem Eur J 14:8507-8513. doi:10.1002/chem.200800718

Teixeira MFS, Martins MS, Silva JC, Kirsch LS, Fernandes OCC, Carneiro ALB, Conti R, Durán N (2012) Amazonian biodiversity: pigments from Aspergillus and Penicillium-characterizations, antibacterial activities and their toxicities. Curr Trends Biotechnol Pharm 6:300-311
Tuli HS, Chaudhary P, Beniwal V, Sharma AK (2014) Microbial pigments as natural color sources: current trends and future perspectives. J Food Sci Technol 52:4669-4678. doi:10.1007/s13197-0141601-6

Velmurugan P, Hur H, Balachandar V, Kamala-Kannan S, Lee KJ (2011) Monascus pigment production by solid-state fermentation with corn cob substrate. J Biosci Bioeng 116:590-594. doi:10.1016/j.jbiosc. 2011.08.009

Velmurugan P, Lee YH, Venil CK, Lakshmanaperumalsamy P, Chae JC, Oh BT (2010a) Effect of light on growth, intracellular and extracellular pigment production by five pigment-producing filamentous fungi in synthetic medium. J Biosci Bioeng 109:346-350. doi:10. 1016/j.jbiosc.2009.10.003

Velmurugan P, Kamala-Kannan S, Balachandar V, Lakshmanaperumalsamy P, Chae JC, Oh BT (2010b) Natural pigment extraction from five filamentous fungi for industrial applications and dyeing of leather. Carbohyd Polym 79:262-268. doi:10. 1016/j.carbpol.2009.07.058

Vendruscolo F, Müller BL, Moritz DE, Oliveira D, Schmidell W, Ninow JL (2013) Thermal stability of natural pigments produced by Monascus ruber in submerged fermentation. Biocatal Agric Biotechnol 2:278-284. doi:10.1016/j.bcab. 2013.03.008

Ventura SPM, Santos-Ebinuma VC, Pereira JF, Texeira MF, Pessoa A, Coutinho JA (2013) Isolation of natural red colorants from fermented broth using ionic liquid-based aqueous two-phase systems. J Ind Microbiol Biot 40:507-516. doi:10.1007/s10295-0131237-y

Wang HS, Pan YM, Tang XJ, Huang ZQ (2006) Isolation and characterization of melanin from Osmanthus fragrans' seeds. LWT-Food Sci Technol 39:496-502. doi:10.1016/j.lwt.2005.04.001

Wrolstad RE, Culve CA (2011) Alternatives to those artificial FD\&C food colorants. Annu Rev Food Sci Technol 3:59-77. doi:10.1146/ annurev-food-022811-101118

Zhang H, Zhan J, Su K, Zhang Y (2006) A kind of potential food additive produced by Streptomyces coelicolor: characteristics of blue pigment and identification of a novel compound, $\lambda$-actinorhodin. Food Chem 95:186-192. doi:10.1016/j.foodchem.2004.12.028 